\title{
Foliar Sprays of Silver Thiosulfate Produce Male Flowers on Female Hemp Plants
}

\author{
Jessica D. Lubell ${ }^{1}$ and Mark H. Brand
}

AdDITIONAL INDEX worDs. Cannabis sativa, cannabidiol, CBD hemp, feminized seed

\begin{abstract}
Summary. Interest in hemp (Cannabis sativa) for its medicinal compounds, cannabidiol (CBD), and $\Delta$-9-tetrahydrocannabidiol (THC), continues to increase. Maximizing yield of CBD and/or THC requires female plants because female inflorescences accumulate significantly greater concentrations of these compounds than male inflorescences. Production of all female seed requires induction of female plants to develop male flowers that produce genetically female pollen. Growers would like access to feminized seed to produce all-female crops. We evaluated the efficacy of $0,0.3$, and $3 \mathrm{~mm}$ silver thiosulfate (STS) applied as a foliar spray (on three occasions 7 days apart) to produce male flowers on four strains of female hemp (having a THC concentration of $\leq 0.3 \%$ ), designated CBD hemp A, CBD hemp B, CBD hemp C, and industrial hemp. Silver thiosulfate at $3 \mathrm{~mm}$ was the most efficacious treatment for all strains. The majority of inflorescences had $100 \% \mathrm{male}$ flowers at $3 \mathrm{~mm}$ STS, and terminal inflorescences had $\geq 95 \%$ conversion to male flowers. Silver thiosulfate at $\mathbf{0 . 3} \mathrm{mm}$ produced partial conversion to male flowers, whereas most inflorescences had around 50\% male flowers, except for CBD hemp A, which demonstrated greater levels of masculinization. At $0.3 \mathrm{~mm}$ STS, terminal inflorescences of CBD hemp A had $91 \%$ conversion to male flowers. This study demonstrates that male flowers can be produced easily and consistently on female plants through application of foliar sprays of STS under short-day conditions.
\end{abstract}

$\mathrm{M}$ edicinal interest in hemp is attributable to its production of unique terpenophenolic substances, called cannabinoids, which are concentrated in the glandular trichomes of the plant (Mechoulam, 1970; Potter, 2014). More than 100 cannabinoids have been identified; however, the most abundant and medicinally important cannabinoids are CBD and THC (de Meijer et al., 2003 ). Recently, interest in the medicinal effects of CBD has increased because, unlike THC, CBD is nonpsychoactive (Russo, 2011; Small, 2015). In the United States, 25 states and the District of Columbia have enacted laws allowing the medicinal use of hemp, and another 17 states allow products that are high in CBD and low in THC (Mead, 2017).

Hemp is an annual dioecious species with females containing homogametic chromosomes XX and males containing heterogametic chromosomes XY (Moliterni et al., 2004). Male plants are taller, more slender,

Department of Plant Science and Landscape Architecture, University of Connecticut, Storrs, CT 06269 This research was supported by CT CAN.

${ }^{1}$ Corresponding author. E-mail: Jessica.lubell@uconn. edu.

https://doi.org/10.21273/HORTTECH04188-18 and have a shorter life cycle than female plants. Sex morphology in hemp is believed to be controlled by an X:autosome balance, where the ratio of X:A (autosomal) chromosomes determines sex by an $\mathrm{X}$ chromosome counting system, and the $\mathrm{Y}$ chromosome is inactive (Negrutiu et al., 2001; Parker, 1990; Shephard et al., 2000; Vyskot and Hobza, 2004). Exogenous application of plant growth regulators can modify or reverse sex morphology in plants (Galoch, 1978). In hemp, auxins, ethylene, and cytokinins promote the formation of female flowers on male plants; gibberellins promote the formation of male flowers on female plants (Galoch, 1978; Mohan Ram and Jaiswal, 1972; Thomas and Vince-Prue, 1997). Mohan Ram and Sett (1982) induced the formation of male flowers on female hemp plants using silver nitrate and STS, which inhibit the action of ethylene.
Monoecious plants occur occasionally in hemp, and cultivars have been selected for use in the production of industrial hemp fiber and seed (Moliterni et al., 2004). Industrial hemp is defined by the 2014 "Farm Bill," Section 7606 of the Agricultural Act 2014 (7 USC 5904) as hemp having a THC concentration of $\leq 0.3 \%$ on a dry weight basis (Mead, 2017). Monoecious hemp cultivars demonstrate greater seed yields and greater crop homogeneity, and are easier to harvest mechanically than dioecious plants (Hall et al., 2012). Sex expression in monoecious hemp is not as well understood as for dioecious plants, but it is believed to be a heritable trait present on the $\mathrm{X}$ chromosome or autosomes (Faux et al., 2014). It has also been suggested that the monoecious state originated from a small translocation from the $\mathrm{Y}$ chromosome, or by one or several mutated genes (Razumova et al., 2016).

In the United States, at least 15 states have enacted legislation authorizing research and agricultural pilot programs related to industrial hemp (National Conference of State Legislatures, 2018). Increased interest in CBD has led to increased cultivation of hemp, but because hemp has been selected for fiber and seed production, it is generally low in CBD content $(2 \%$ to $4 \%$ ) (Mead, 2017). Therefore, the development of hemp cultivars with increased CBD content is a current breeding objective (Caplan et al., 2017; Soler et al., 2017).

Female plants are preferred for cannabinoid production because females accumulate, predominantly in the inflorescences, significantly greater cannabinoid content than male plants (Small, 2015). Rahn et al. (2016) and Soler et al. (2017) report that hemp growers are using hormones or chemicals like STS to make feminized seed, in which $100 \%$ of the seed is female. Mohan Ram and Sett (1982) suggest STS can be used to make male flowers with viable pollen on female hemp

\begin{tabular}{llll}
\hline $\begin{array}{l}\text { Units } \\
\begin{array}{l}\text { To convert U.S. to SI, } \\
\text { multiply by }\end{array}\end{array}$ & U.S. unit & SI unit & $\begin{array}{l}\text { To convert SI to U.S., } \\
\text { multiply by }\end{array}$ \\
\hline 29.5735 & $\mathrm{fl} \mathrm{oz}$ & $\mathrm{mL}$ & 0.0338 \\
2.54 & $\mathrm{inch}(\mathrm{es})$ & $\mathrm{cm}$ & 0.3937 \\
28.3495 & $\mathrm{OZ}$ & $\mathrm{g}$ & 0.0353 \\
1 & $\mathrm{ppm}$ & $\mathrm{mg} \cdot \mathrm{L}^{-1}$ & 1 \\
$\left({ }^{\circ} \mathrm{F}-32\right) \div 1.8$ & ${ }^{\circ} \mathrm{F}$ & ${ }^{\circ} \mathrm{C}$ & $\left({ }^{\circ} \mathrm{C} \times 1.8\right)+32$
\end{tabular}


plants, but their methods are not directly translatable to commercial applications. Male flowers induced on genetically female plants will produce pollen containing only $\mathrm{X}$ gametes, which when crossed with eggs from female plants result in all-female seed (Mohan Ram and Sett, 1982). Foliar sprays of STS have been effective at blocking ethylene production and extending the flowering time for several different species of ornamental plants (Cameron and Reid, 1981, 1983). Green (2015) describes using a single foliar spray of STS to produce feminized hemp seed. This method has been shared among growers online, but this information is not based on scientific research. There are no published reports about using foliar sprays of STS to produce feminized hemp seed. Therefore, the objective of this work was to evaluate the efficacy and rate of foliar sprays of STS for inducing male flowers and producing female seed for different strains of hemp.

\section{Materials and methods}

This study was conducted two times on three different strains of CBD hemp-strains A, B, and Cthat differed from one another in their branching density, stem color, and leaf size. One strain of industrial hemp was studied. In the first replication of this study, CBD hemp strains $\mathrm{A}$ and $\mathrm{C}$, and the industrial hemp strain were used; in the second replication of this study, CBD strains B and C, and the industrial hemp strain were used. Plants used in the study were propagated vegetatively from female mother plants of each strain. The industrial hemp female mother plant was selected from a population of seedlings that were female, male, or monoecious.

Rooted cuttings were potted into $307-\mathrm{mL}$ square containers filled with a peatmoss-based grower mix (Fafard 3B Grower Mix; Fafard, Agawam, MA) and top-dressed with controlled-release fertilizer (Osmocote Plus $15 \mathrm{~N}-3.9 \mathrm{P}-10 \mathrm{~K}$ 5- to 6month formulation; Everris NA, Dublin, $\mathrm{OH})$ at $2.5 \mathrm{~g} /$ container. Plants were allowed to grow and establish for $\approx 14 \mathrm{~d}$ in a greenhouse with set points of $21 / 17^{\circ} \mathrm{C}$ day/ night. Plants were provided long-day $(16 \mathrm{~h})$ conditions using natural daylight that was extended with 600-W high-pressure sodium (HPS) lamps (Phantom HPS 600W; Hydrofarm, Petaluma, CA). During this time, plants were hand fertigated using a soluble fertilizer (Peters $20 \mathrm{~N}-$ 8.7P-16.6K; Scotts, Marysville, $\mathrm{OH}$ ) at $100 \mathrm{ppm}$ nitrogen $(\mathrm{N})$ at every irrigation $(200 \mathrm{~mL} /$ container $)$. Plants were $\approx 6$ inches high with two shoots when foliar sprays of STS were initiated. Silver thiosulfate solutions $(0.3$ and $3 \mathrm{~mm}$ ) were prepared by mixing silver nitrate with STS in a molar ratio of $1: 4$, per Cameron and Reid (1981). Plants were sprayed to runoff (about $20 \mathrm{~mL} /$ plant) on three occasions, $7 \mathrm{~d}$ apart, beginning on 30 Apr. 2018 for the first replication and on 14 May 2018 for the second replication of this study. Control plants received sprays of water only. On 30 Apr. and 14 May, plants began receiving shortday conditions of $\approx 8 \quad \mathrm{~h}$ using a blackout curtain to initiate the flowering stage. During the flowering stage, plants received a soluble fertilizer (Peters $15 \mathrm{~N}-12.9 \mathrm{P}-12.5 \mathrm{~K}$, Scotts) at $100 \mathrm{ppm} \mathrm{N}$ as described previously.

The experiment was a randomized complete block design with two factors: three STS treatments and three strains, with three replicates for each factor combination. Each potted plant was an experimental unit. One week after the third and final STS spray, the number of male and female flowers per terminal inflorescence was counted for two terminal inflorescences per plant, which were averaged, and the percentage of male flowers per inflorescence was calculated for each plant. The degree of masculinization was evaluated using a visual rating. Each inflorescence per plant was rated for degree of masculinization using a scale of 1 to 5 , where 1 represented $0 \%$ male flowers (allfemale inflorescence), 2 represented $1 \%$ to $30 \%$ male flowers (strongly female inflorescence), 3 represented $31 \%$ to $60 \%$ male flowers (about equivalent male and female flowers), 4 represented $61 \%$ to $99 \%$ male flowers (strongly male inflorescence), and 5 represented 100\% male flowers (all-male inflorescence) (Fig. 1). SAS software (version 9.2; SAS Institute, Cary, NC) was used for statistical analysis.

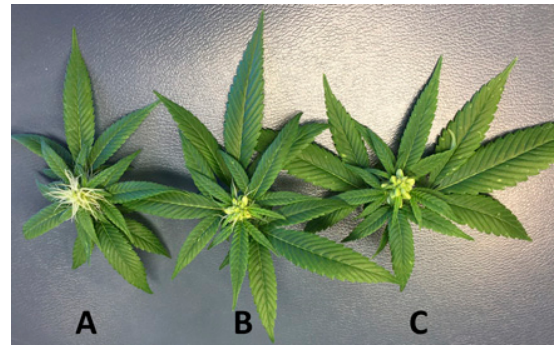

Fig. 1. Photograph of (A) an allfemale inflorescence, (B) an inflorescence with about equivalent male and female flowers, and (C) an all-male inflorescence from female cannabidiol (CBD) hemp strain C plants.

Analysis of variance using the PROC MIXED procedure indicated no significant difference between replications one and two of this study, so the data were combined. Differences between STS treatments within strain for the percentage of male flowers per terminal inflorescence were determined using multiple comparisons for proportions and Tukey's honestly significant difference test (Williams and LeBlanc, 1995).

\section{Results}

Between 14 and $21 \mathrm{~d}$ after the first STS spray treatment, plants transitioned from first flowers to full flowering. Untreated control plants of all four hemp strains produced only female flowers, as expected (Fig. 2). This result confirmed that our starting plants were genetically female and there was no induction of male flowers resulting from other factors. For all strains, the $0.3-\mathrm{mm}$ STS treatment produced partial conversion to male inflorescences (Fig. 2). At $0.3 \mathrm{~mm}$ STS, inflorescences were generally a mix of male and female flowers. CBD hemp A at $0.3 \mathrm{~mm}$ STS produced more inflorescences with high levels of masculinization than the other hemp strains. At $0.3 \mathrm{~mm}$ STS, CBD hemp $B$ and $C$, and industrial hemp inflorescences ranged from $25 \%$ to $75 \%$ male flowers, centering around $50 \%$ male flowers per inflorescence. The most complete inflorescence conversion to male flowers occurred at $3 \mathrm{~mm}$ STS for all hemp strains. At $3 \mathrm{~mm}$ STS, the majority of inflorescences had $100 \%$ male flowers and the remaining inflorescences had $75 \%$ male flowers. 

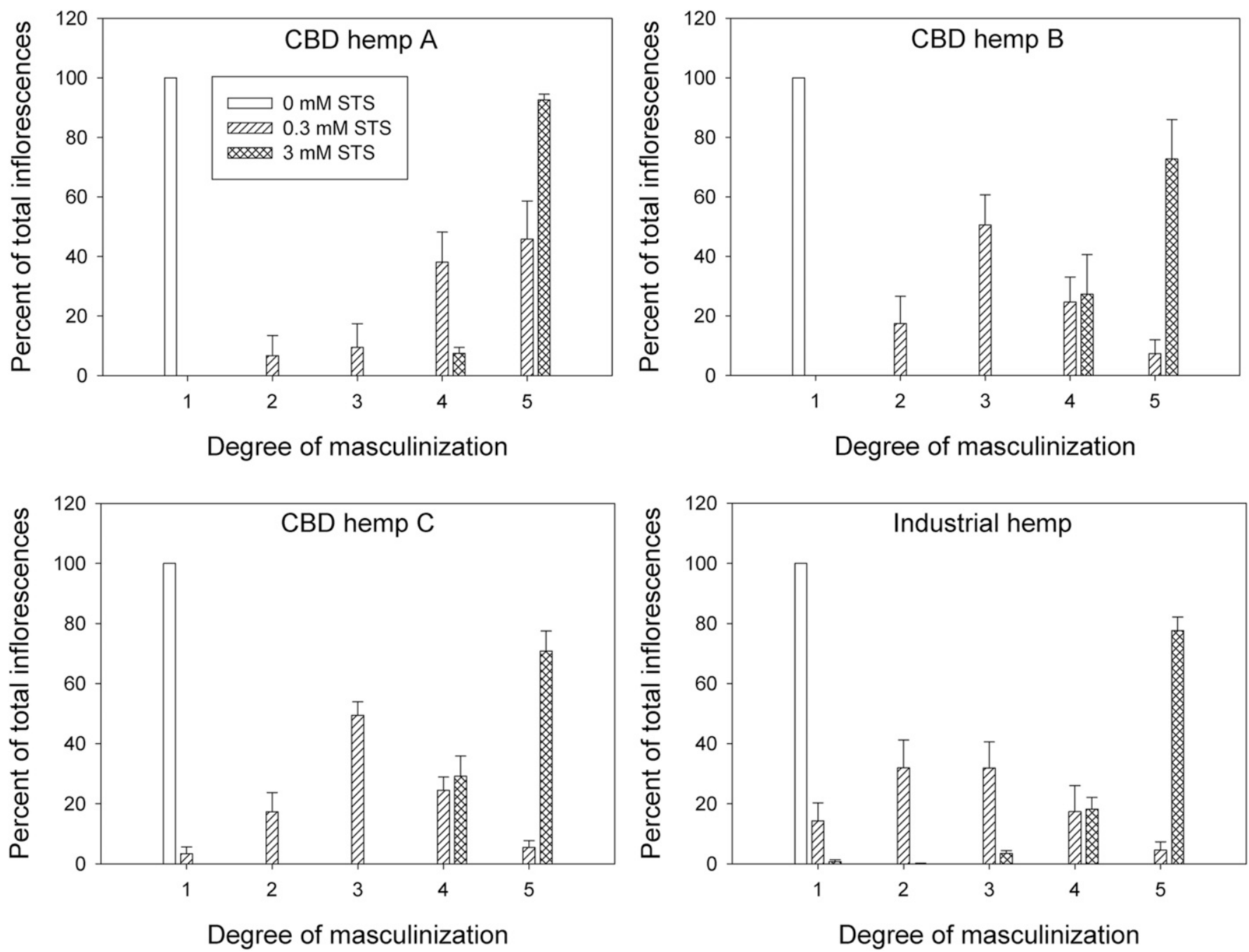

Fig. 2. Distribution of masculinization ratings among inflorescences of three different cannabidiol (CBD) hemp strains and one industrial hemp strain treated with foliar sprays of $0,0.3$, or $3 \mathrm{~mm}$ silver thiosulfate (STS) applied three times at 7 -d intervals. Values are the percentages of inflorescences per plant that received each masculinization rating from 1 to 5 , where $1=0 \%$ male flowers (all female inflorescence), $2=1 \%$ to $30 \%$ male flowers (strongly female inflorescence), $3=31 \%$ to $60 \%$ male flowers (about equivalent male and female flowers), $4=61 \%$ to $99 \%$ male flowers (strongly male inflorescence), and $5=100 \%$ male flowers (all male inflorescence). Vertical bars indicate \pm SE.

In counting the actual number of male flowers per terminal inflorescence, $3 \mathrm{~mm}$ STS produced $100 \%$ conversion to male flowers for CBD hemp $\mathrm{A}$ and industrial hemp, and 97\% and $95 \%$ for CBD hemp B and C, respectively (Table 1 ). Depending on the hemp strain, STS at $0.3 \mathrm{~mm}$ converted between $42 \%$ and $91 \%$ female flowers to male flowers. CBD hemp A had the greatest rate of conversion to male flowers at $91 \%$ and industrial hemp had the lowest conversion rate at $42 \%$.

Male flowers that developed on genetically female plants produced pollen. However, the pollen did not appear to be as copious or freely released as observed on true genetically male plants. Pollen from masculinized flowers from CBD hemp strain B was used to fertilize female flowers on CBD hemp strain $\mathrm{C}$ to document that this method could be used successfully to generate all female seed. The pollen produced seed, which were harvested, germinated, and exposed to short-day conditions, and their sex was confirmed to be female.

\section{Discussion}

Overall, STS at $3 \mathrm{~mm}$ was the most effective treatment for producing the greatest number of male flowers on female hemp plants. Green (2015) suggested that female hemp plants can be masculinized using a single foliar spray of $0.3 \mathrm{~mm}$ STS, but did not provide any information about the percent conversion to male flowers. We did not find three foliar sprays of $0.3 \mathrm{~mm} S T S$ to be as effective for producing male flower formation as three foliar sprays of $3 \mathrm{~mm}$ STS. However, there may be specific strains, such as CBD hemp A, which produce primarily male flowers with STS concentrations less than $3 \mathrm{~mm}$.

Silver thiosulfate has been used to extend the vase life of cut flowers by blocking the effect of ethylene (Farnham et al., 1981; Veen and van de Geijn, 1978). A similar action of ethylene blocking by STS is likely responsible for the production of male flowers on female hemp plants in our study. It is generally believed that ethylene blocking is extended when a series of sprays of 
Table 1. Percent of male flowers per terminal inflorescence for three different cannabidiol (CBD) hemp strains and one industrial hemp strain treated with 0 , 0.3 , or $3 \mathrm{~mm}$ silver thiosulfate (STS) applied as a foliar spray three times at $7-\mathrm{d}$ intervals.

\begin{tabular}{lcc}
\hline Strain & Treatment (mM STS) & Male flowers $/$ inflorescence (\%) \\
\hline CBD hemp A $(\mathrm{n}=3)$ & 0 & $0 \mathrm{c}^{\mathrm{z}}$ \\
& 0.3 & $91 \mathrm{~b}$ \\
& 3 & $100 \mathrm{a}$ \\
CBD hemp B $(\mathrm{n}=3)$ & 0 & $0 \mathrm{c}$ \\
& 0.3 & $50 \mathrm{~b}$ \\
& 3 & $97 \mathrm{a}$ \\
CBD hemp C $(\mathrm{n}=6)$ & 0 & $0 \mathrm{c}$ \\
& 0.3 & $69 \mathrm{~b}$ \\
& 3 & $95 \mathrm{a}$ \\
Industrial hemp $(\mathrm{n}=6)$ & 0 & $0 \mathrm{c}$ \\
& 0.3 & $42 \mathrm{~b}$ \\
& 3 & $100 \mathrm{a}$ \\
\hline
\end{tabular}

${ }^{\mathrm{z}}$ Differences between treatments within strains, indicated by different letters, were determined using multiple comparisons for proportions and Tukey's test at $P \leq 0.05$.

STS is used compared with a single spray of STS (Reid et al., 1980). It may be possible to induce male flowers on genetically female hemp using other ethylene perception inhibiting chemicals such as 1 methylcyclopropene.

Mohan Ram and Sett (1982), using 25 to $100 \mu \mathrm{g}$ STS applied directly to the growing shoot tip of female hemp plants, were able to produce male flowers. However, they also noted severe necrosis on young leaves covering shoot tips and suspended apical growth for 20 to $25 \mathrm{~d}$ before lateral budbreak and subsequent flower formation. In comparison, we did not observe any plant phytotoxicity or delay in flower development. Furthermore, we were able to achieve $95 \%$ to $100 \%$ conversion to male flowers for all hemp strains, whereas Mohan Ram and Sett (1982) reported $\approx 60 \%$ to $80 \%$ conversion.

Producers and breeders should be able to masculinize female hemp plants routinely by using short-day conditions of $\approx 8 \mathrm{~h}$ and three foliar sprays of $3 \mathrm{~mm}$ STS at weekly intervals. We suspect that this method will be applicable for a broad range of genetically diverse hemp genotypes. Pollen produced by male flowers on genetically female plants can be used to produce all-female seed, but growers and breeders should be aware that pollen output may be reduced compared with pollen output from genetically male plants.

\section{Literature cited}

Cameron, A.C. and M.S. Reid. 1981. The use of silver thiosulfate anionic complex as a foliar spray to prevent flower abscission of zygocactus. HortScience 16:761-762.

Cameron, A.C. and M.S. Reid. 1983. Use of silver thiosulfate to prevent flower abscission from potted plants. Scientia Hort. 19:373-378.

Caplan, D., M. Dixon, and Y. Zheng. 2017. Optimal rate of organic fertilizer during the vegetative-stage for cannabis grown in two coir-based substrates. HortScience 52:1307-1312.

de Meijer, E.P.M., M. Bagatta, A. Carboni, P. Crucitti, V.M.C. Molterni, P. Ranalli, and G. Mandolino. 2003. The inheritance of chemical phenotype in Cannabis sativa L. Genetics 163:335-346.

Farnham, D.S., M.S. Reid, and D.W. Fujino. 1981. Effects of STS on shattering in snapdragons. Acta Hort. 113:39-43.

Faux, A., A. Berhin, N. Dauguet, and P. Bertin. 2014. Sex chromosomes and quantitative sex expression in monoecious hemp (Cannabis sativa L.). Euphytica 196:183-197.

Galoch, E. 1978. The hormonal control of sex differentiation in dioecious plants of hemp (Cannabis sativa). Acta Soc. Bot. Pol. 47:153-162.
Green, G. 2015. The cannabis breeder's bible. Green Candy Press, San Francisco, CA.

Hall, J., S.P. Bhattarai, and D.J. Midmore. 2012. Review of flowering control in industrial hemp. J. Nat. Fibers 9:23-36.

Mead, A. 2017. The legal status of cannabis (marijuana) and cannabidiol (CBD) under U.S. law. Epilepsy Behav. 70:288291.

Mechoulam, R. 1970. Marihuana chemistry. Science 168:1159-1166.

Mohan Ram, H.Y. and V.S. Jaiswal. 1972. Induction of male flowers on female plants of Cannabis sativa by gibberellins and its inhibition by abscisic acid. Planta 105:263-266.

Mohan Ram, H.Y. and R. Sett. 1982. Induction of fertile male flowers in genetically female Cannabis sativa plants by silver nitrate and silver thiosulphate anionic complex. Theor. Appl. Genet. 62: 369-375.

Moliterni, V.M.C., L. Cattivelli, P. Ranalli, and G. Mandolino. 2004. The sexual differentiation of Cannabis sativa L.: A morphological and molecular study. Euphytica 140:95-106.

National Conference of State Legislatures. 2018. State industrial hemp statutes. 15 June 2018. <http://www.ncsl. org/research/agriculture-and-ruraldevelopment/state-industrial-hempstatutes.aspx $>$.

Negrutiu, I., B. Vyskot, N. Barbacar, S. Georgiev, and F. Moneger. 2001. Dioecious plants: A key to the early events of sex chromosome evolution. Plant Physiol. 127:1418-1424.

Parker, J.S. 1990. Sex chromosomes and sexual differentiation in flowering plants. Chromosomes Today 10:187-198.

Potter, D.J. 2014. A review of the cultivation and processing of cannabis (Cannabis sativa L.) for production of prescription medicines in the UK. Drug Test. Anal. 6:31-38.

Rahn, B., B.J. Pearson, R.N. Trigiano, and D.J. Gray. 2016. The derivation of modern cannabis varieties. Crit. Rev. Plant Sci. 35:328-348.

Razumova, O.V., O.S. Alexandrov, M.G. Divashuk, T.I. Sukhorada, and G.I. Karlov. 2016. Molecular cytogenetic analysis of monoecious hemp (Cannabis sativa L.) cultivars reveals its karyotype variations and sex chromosomes constitution. Protoplasma 253:895-901.

Reid, M.S., J.L. Paul, M.B. Farhoomand, A.M. Kofranek, and G.L. Staby. 1980. Pulse treatments with the silver thiosulfate 
complex extend the vase life of cut carnations. J. Amer. Soc. Hort. Sci. 105:2527.

Russo, E.B. 2011. Taming THC: Potential cannabis synergy and phytocannabinoidterpenoid entourage effects. Brit. J. Pharmacol. 163:1344-1364.

Shephard, H.L., J.S. Parker, P. Darby, and C.C. Ainsworth. 2000. Sexual development and sex chromosomes in hop. New Phytol. 148:397-411.

Small, E. 2015. Evolution and classification of Cannabis sativa (marijuana, hemp) in relation to human utilization. Bot. Rev. 81:189-294.

Soler, S., P. Gramazio, M.R. Figas, S. Vilanova, E. Rosa, E.R. Llosa, D. Borras, M. Plazas, and J. Prohens. 2017. Genetic structure of Cannabis sativa var. indica cultivars based on genomic SSR (gSSR) markers: Implications for breeding and germplasm management. Ind. Crops Prod. 104:171-178.

Thomas, B. and D. Vince-Prue. 1997. Photoperiodism in plants. 2nd ed. Academic Press, London, UK.
Veen, H. and S.C. van de Geijn. 1978. Mobility and ionic form of silver as related to longevity of cut carnations. Planta 140:93-96.

Vyskot, B. and R. Hobza. 2004. Gender in plants: Sex chromosomes are emerging from the fog. Trends Genet. 20:432-438.

Williams, R.H. and W.G. LeBlanc. 1995. Pairwise comparisons among proportions. Educ. Psychol. Meas. 55:445-447. 